<smiles>CC(C#N)(CCC(=O)O)N=NC(C)(C#N)CCC(=O)O</smiles>

which leads to polymers containing terminal carboxyl groups. These latter species are coupled together by diols or other suitable bifunctional reagents. These two techniques were successfully applied for the preparation of block copolymers containing methylmethacrylate and either acrylonitrile or styrene. The composition and size distribution of some of these block copolymers could be calculated.

Drs. P. W. Allen, G. Ayrey and D. T. Turner (British Rubber Producers Research Association) gave lectures dealing with graft copolymers (I), made from natural rubber and polymethylmethacrylate. The copolymer (I) was prepared by the polymerization of methylmethacrylate, initiated by $\gamma$-radiation, this reaction being carried out in the presence of natural rubber. The influence of the purity of the natural rubber and of the methylmethacrylate, field intensity, concentration of methylmethacrylate and other variables on the rate of formation, yield and structure of the copolymer (I) were investigated. An alternative method of preparing the copolymer (I) consists in the benzoylperoxide initiated polymerization of methylmethacrylate, this process being again carried out in the presence of natural rubber. If azoisobutyronitrile is used as initiator, polymethylmethacrylate is formed, but no copolymer $(\mathbf{I})$. The cause of this specific initiator effect and some aspects of the mechanism have been investigated by using initiators labelled with carbon-14. In these investigations the separation of copolymer (I) from the natural rubber and methylmethacrylate was carried out by fractional precipitation, fractional extraction and turbidimetric titration methods. For purposes of characterization of (I) its molecular weight was determined, and after degradation of the rubber component with ozone, the molecular weight of the remaining polymethylmethacrylate component was measured.

\section{ELECTRONIC INSTRUMENTS EXHIBITION, MANCHESTER}

$\mathrm{T}$

HE Institution of Electronics is a nation-wide organization, but its headquarters are now in the north of England and its main centre of activity is Manchester, where the exhibition of electronic instruments organized by the Northern Division has, since the War, become established as an annual event. The twelfth annual Electronics Exhibition and Convention was held during July 11-17 at the Manchester College of Science and Technolog. About sixty manufacturers and other organizations exhibited their products, and the Exhibition was attended by about 14,000 visitors. Most of the exhibits consisted of commercially available equipment, which was in some cases shown in action, and there was also a special section for equipment still in the research stage. A programme of lectures and films ran concurrently with the Exhibition, and these were well attended.
Earlier Exhibitions have included a number of sections which would appeal to a wide public--for example, sound-reproducing equipment and electronic musical instruments. However, these were absent from this year's Exhibition, which was clearly aimed, even more than usual, at the professional user, and perhaps the manufacturer, of electronic instruments. For the latter, components and even such things as racks and chassis were shown by several firms. The Exhibition included an impressively wide range of instruments, of which a few only, a personal selection, can be mentioned. There was, in any event, little that was really new, although there were some items which had appeared since last year's Exhibition.

A flying-spot microscope which was shown by Cinema-Television, Ltd., is fitted with arrangements for counting the number of particles in its field, and their size distribution is obtained by successive counts with different adjustments of a size discriminator. A magnetic 'memory' in the counting unit ensures that a particle large enough to be scanned on several successive lines is only counted once: this is only defeated by particles the shape of which is re-entrant in the scanning direction, or perforated.

Another exhibit by Cinema-Television, Ltd., was a photographic contact printer designed to produce satisfactory contact prints from patchy negatives. A rather large spot of light from a cathode-ray tube scans, raster-wise, the negative with the printing paper in contact. The light passing through them both falls on a photocell the output of which is used to produce limited variations in the brightness of the spot. The broad scanning lines produced by the large spot overlap considerably, so that the definition is that of the negative and no scanning lines appear on the print. The instrument, in fact, carries out automatically the hand-shading usually employed in the printing of uneven negatives. Its cost, more than $£ 900$, will presumably limit it to large-scale users, and examples were given of its use in connexion with aerial photography and the commercial printing of amateurs' negatives. Another version which will make enlargements is to be produced.

An exhibit which was at least new to these Exhibitions was a version of the Land camera made by Langham Thompson, Ltd. In its present form it is intended for photographing cathode-ray tube displays and is fitted with an $f / 3.5$ lens and a singlespeed shutter. The novelty is that instead of film it uses special photographic paper with pods of developing and fixing chemicals attached to it at regular intervals. When the paper is wound on after exposure, rollers burst one of the pods and the chemicals are spread on the paper while it is still inside the camera. After waiting for one minute the paper is pulled out and emerges as a finished positive print. The material available is very fast ( $35^{\circ}$ Scheiner) and some twice as fast is promised soon. The operating cost is about $2 s .6 d$. a print (4 in. $\times 3$ in.).

Of the many cathode-ray oscilloscopes on show, the most novel were probably those by Cossor, Ltd., which are available only as kits of parts, but at little more than half the cost of comparable finished instruments. They use printed circuits throughout, and the made-up samples on show were clean-looking jobs-in fact, one suspects that the relative absence of wiring will greatly reduce the tangled web which sometimes results from amateur construction, as well as making the circuit characteristics more predictable. 
Three kits are at present available, for single-beam and double-beam oscilloscopes and for a valve voltimeter.

Several counting and scaling units were shownone which provided some relatively light relief was arranged to measure one's reaction time. The victim was required to press a button when some miniature traffic lights turned red. The time taken in microseconds was duly counted and displayed; it was usually of the order of $2 \times 10^{5}$.

The research section showed a change from previous years in that there were no university exhibits, but three by national organizations : the Admiralty, Atomic Energy Research Establishment, Capenhurst, and the British Railways Research Department. The last-named was showing a train control system which automatically applies the brakes of a train passing a signal at danger. The Hall effect in an indium antimonide probe attached to the train is used for detecting the energization of an electromagnet between the tracks. This equipment, which is still in the experimental stage, is intended as an allelectronic successor to the electro-mechanical system now going into service.

J. E. GEAKE

\section{ENGINEERING TRAINING IN THE BRITISH BROADCASTING CORPORATION}

$\mathrm{T}^{1177}$

$\mathrm{HE}$ series of B.B.C. Engineering Monographs, to which reference has already been made in Nature $(177,519 ; 1956)$, provide a continuous description of the technical equipment and operation of the Corporation, developed and applied to the conduct of its duties as a public broadcasting authority. Among these duties is that of recruiting and training the large numbers of engineers and technical personnel required by the organization.

B.B.C. Engineering Monograph No. $11^{*}$ is entitled "Engineering Training in the B.B.C.", by Dr. K. R. Sturley, and this describes the work of the training department which came into existence about eleven years ago, and is established at Wood Norton Hall, Evesham. Here there is accommodation for up to two hundred residential students, and full teaching facilities during various courses of instruction, which vary in length from one or two up to twelve weeks. The aims of the training department are to develop the skill and capabilities of staff, to encourage them to adopt a constructive attitude to new ideas and to increase the efficiency of the individual to the mutual benefit of himself and of the organization to which he belongs. Every attempt is made to avoid duplicating the basic training in electrical engineering which is provided by universities and technical colleges; the department concentrates on the application of basic principles to the equipment and methods used in broadcasting.

Some of the courses provide training for newly recruited entrants to the operating and technical assistant staffs, where the instruction varies from the arrangement of studio lighting to the maintenance of high-power transmitters. More advanced courses are intended to provide junior staff with opportunities for promotion in the operations or maintenance

* B.B.C. Engineering Monograph No. 11 : Engineering Training in the B.B.C. By Dr. K. Re fields. Students with the appropriate national technical qualification may be exempt from the first part of this course; they are then required to take the second part, dealing with broadcasting equipment and technique which cannot be a part of the syllabus leading to an academic award. At a more advanced level there is a graduate apprentice course of two years duration, involving attachment to other departments of the B.B.C. as well as the training department. Its purpose is to produce a wellbalanced man of wide experience, who will eventually qualify for corporate membership of his appropriate professional institution. Two types of graduates are sought here : one intended for specialist departments such as those conducting research or design and development; the other is intended to fill a senior position in the operation and maintenance branch, where the ability to supervize staff and to deal coolly and efficiently with an emergency are essential qualities.

Under Dr. Sturley as head of the Training Department, the instruction is organized in four sections dealing with fundamentals, radio-frequency transmission, studio and recording techniques, and operations; a fully qualified staff of lecturers, demonstrators and laboratory assistants is provided. A separate section of staff is responsible for the production of training manuals, and also of booklets on such subjects as television lighting, frequency modulation and slot aerials, which are of great value to the technical staff of the Corporation.

During July 22-26 last, a summer school was held at Wood Norton and was attended by some thirty members of the staffs from the engineering and physics departments of universities and technical colleges in the United Kingdom. In addition to inspecting the Training Department and witnessing demonstrations in the laboratories, a series of lectures was given by members of various departments of the B.B.C., the subjects ranging from training, research and operation to the presentation of science in sound and television broadcasting. The programme naturally included talks on the engineering and technical requirements of the B.B.C. staffs, and there was ample opportunity for both formal and informal discussion between the visitors and the resident staff. This short and very successful summer school, which was a repetition on an expanded scale of one held in 1952 , should do much to strengthen the ties between the Corporation and the colleges on which it must rely for its recruits.

\section{TRAINING OF FACTORY WORKERS}

\footnotetext{
THE effectiveness of the training of factory workers has an important bearing on industrial productivity. Developments of production methods in this century, particularly in some of the newer industries, have made it possible to employ large proportions of semi-skilled and unskilled workers in the factories; the training of this kind of operative has been relatively neglected until recent years, presumably on the assumption that, because his work was simple in comparison with that of the craftsman, he would be able to learn it with a minimum of assistance.
} 